\title{
Holding the Child (and Practitioner) in Mind? \\ Youth Justice Practitioners Experiences Supervising \\ Young People Displaying Sexually Harmful Behaviour
}

\section{Andrew Myles-Wright and Claire Nee}

\begin{abstract}
This qualitative study explored the lived experiences of youth justice practitioners supervising young people (under 18 years old) displaying sexually harmful behaviour within the Youth Justice System in the UK, as little is currently known about the challenges faced when working with this vulnerable group. Five practitioners from two Youth Offending Services (YOS) participated in individual semistructured interviews, which were subjected to thematic analysis while also analysing the performative function of language used. The analysis identified an overarching theme of 'systemic unease', which contained two sub-themes surrounding 'unease with the self, and wider YOS personnel' and 'unease working with partner agencies'. The findings illuminate critical issues regarding future practice with this under-researched group of young people within the broader context of youth justice, which require further exploration and investigation. The 'dual relationship problem' involving tension between risk management and therapeutic alliance is explored in relation to this group. The Moral Acquaintance Model and the Model of Dynamic Adaptation are suggested as helpful approaches to support practitioners and multi-agency professionals going forward in this area.
\end{abstract}

Keywords: thematic analysis, youth justice system, youth offending service (YOS), dual relationship, practitioner experiences, sexually harmful young people 


\section{Introduction}

Between April 2013 and March 2014, nearly 91,000 offences were committed by young people under 18 years of age in England and Wales that resulted in a formal conviction in Court. 1,653 were sexual offences, which accounts for $2 \%$ of all offences committed by young people under 18 years of age (Youth Justice Board/Ministry of Justice, 2015). In the U.S. in 2015, the Department of Justice National Sex Offender Public Website (NSOPW) highlighted 23\% of reported cases of child sexual abuse were perpetrated by young people under the age of 18 .

Research has primarily sought to explore professional practice with adult sex offenders Almost no literature exists examining practice with young people (under 18 ) displaying sexually harmful behaviour in any detail. We define sexually harmful behaviour in line with Calder (1999) cited by the Centre for Youth and Criminal Justice as "any form of sexual activity with another individual, that they have powers over by virtue of age, emotional maturity, gender, physical strength, intellect and where the victim in this relationship has suffered sexual exploitation" (CYCJ, n.d; p. 3).

Where available, most studies explore issues from the young person's perspective, focussing on their (and their families) experience of assessment and intervention (Becker, 1998; Bremer, 1998; Franey, Viglione, Wayson, Clipson, \& Brager, 2005; Hackett \& Masson, 2006; Hackett, Phillips, Balfe, \& Masson, 2012). Only one recent study explores the impact of working with this population on practitioners (Almond, 2013).

Clearly, there is a lack of research exploring practitioners' experiences this vulnerable group. Recent national inspections in the UK (CJJI, 2013) have highlighted concerns regarding the effectiveness of agencies and insufficient specialist training when working with this particular population, and such findings are likely to be mirrored in other countries, as the experience of economic downturn and consequent challenges regarding training and support of staff is doubtlessly a global issue. Although statistical data may suggest the prevalence of sexual offences committed by young people to be low, behaviour 'seriousness' still requires an appropriate approach to assessment 
and intervention to address the risk of future harmful behaviour, and to ensure both current and potential future victims are appropriately safeguarded.

The purpose of this study was to take a first step in addressing this gap in knowledge and understanding by exploring the lived experiences of youth justice practitioners supervising young people with sexually harmful behaviour. It had two primary aims: to expose issues arising from daily working practice by providing youth justice practitioners with an opportunity to share their livedexperiences, and to contribute to a currently under-developed research base within youth justice globally, in order to "bring us together to tackle shared challenges" and to ensure practitioners question "what are our responsibilities to those doing similar jobs to ourselves elsewhere in the world?" (Allardyce, 2016).

The issue of young people displaying sexually harmful behaviour came onto the agenda in the 1990's in the UK including concerns around denial and minimisation of the problem by professionals, a lack of a 'joined-up' approach amongst partner agencies, and a distinct lack of specialist provision (National Children's Home, 1992). As a result, multi-agency Youth Offending Service's (YOS) were set up to improve provision and coordinate with child welfare services for young offenders generally (Home Office, 1999). The fundamental aim of YOS is to deal with young people under 18 years old to reduce their risk of offending and re-offending, and to provide counsel and rehabilitation to those who do offend. A wide variety of work is delivered in order to achieve their aims, which may include supervising young people who have been ordered by the court to serve sentences in the community or in the secure estate and organising meetings between offenders and victims to encourage apologies and reparation.

In parallel, international research began to emerge which sought to explore the impact of working with adult sex offender clients upon practitioners. Farrenkopf (1992) indicated 54\% of professionals reported being initially hopeful and expectant, to cynical and pessimistic about the prospect of client change, with $45 \%$ also experiencing the 'dulling' of their own emotions due to the frustration experienced when working with clients in denial. Of equal concern, was the psychological 
impact upon practitioners' personal lives, where emotional distancing from friends and family was frequently experienced. More recently, focus groups with parole officers responsible for the provision of post-release supervision of adult sex offenders indicate experiences of secondary trauma (Severson \& Pettus-Davis, 2013), involving intrusive thoughts, difficulties sustaining attention, hyper-vigilance and disrupted sleep patterns (Collins \& Nee, 2010; Cunningham, 2003; Figley, 1993).

All-in-all, these more recent studies on those working with adult sex offenders echo a theme found in earlier work on inadequate training, supervision and support when working with this population (Epps, 1993; Lea, Auburn \& Kibblewhite, 1999; Weekes, Pelletier, \& Beaudette, 1995).

A single, dated interview study on social work practitioners working with young sex offenders complemented this view highlighting a lack of knowledge of theoretical perspectives and empirical research, and perceiving young people as "[...] 'innocents', and not sexual beings, coupled with the discomfort of professionals about matters of sexuality" (Ladwa-Thomas \& Sanders, 1999, p. 57). This was commensurate with a sense of lack of training and support felt in young offender practitioners generally (Henniker, Foster \& Griffin, 2000). At the turn of the millennium, professionals believed that multi-agency teams would provide "[...] the ideal solution in meeting the 'focused needs' of young sexual abusers" (Ladwa-Thomas \& Sanders, 1999, p. 59). Their inception within Local Authorities in 2000 meant that the 'ideal solution' to meet the needs of these young people had arrived. It would be reasonable, therefore, to expect significant improvements in provision for young people and support for professionals from then on.

Concurrently, the AIM project was launched (Print, Morrison \& Henniker, 2000) drawing together best practice in assessment and treatment from youth justice and health perspectives. However, by 2004, continuing sense of lack of appropriate training to deliver interventions to sexually harmful adolescents (Masson \& Hackett, 2004). For instance, $75 \%$ of respondents identified supervision arrangements were partially adequate or non-existent.

Little appears to have been done to address this problem over the last decade due to successive financial cutbacks. The consequent restructuring and change in the Youth Justice System 
in the UK likely mirrored around the world has not helped. Fragmentary attempts to improve training through online packages (e.g. 'Young people who sexually abuse' by Grimshaw, 2008) are unlikely to be able to address the specific needs of practitioners' identified within the research literature. One isolated recent study of 16 practitioners working with sexually harmful young people conducted by Almond (2013) found some positive outcomes; participants did not experience their work as inherently stressful, with the positive elements of practice outweighing those elements that maybe considered negative. They felt, however, that their employing organisation (a charity, rather than YOS) impacted unfavourably upon resilience, which may have been due to organisational changes occurring at the time the study was conducted.

Without truly offering a voice to youth justice practitioners associated with supervising this challenging population, it is not possible to understand how to most effectively respond to their needs for forensic practice. It is well known that delivering interventions to adult sex offending populations is a highly demanding task (e.g. Ennis \& Horne, 2003) and recently, focus has turned to the dual relationship tensions (Ward, 2013) experienced by criminal justice practitioners, in which the overwhelming emphasis on management of risk prevents any real engagement in therapeutic intervention (Gannon \& Ward, 2014). Given the recurrent negative themes reported in working with adult sex offenders, it seemed particularly important to examine the issues surrounding working with potentially more vulnerable and challenging clients due to their age. Further, exploring the needs of practitioners is paramount if the literature surrounding the 'therapeutic alliance' is to be embraced as promoting and supporting effective change within the client. Behaviour change is facilitated through a robust therapeutic alliance driven by key skills and underpinning knowledge; any efforts to support and facilitate change with young people with sexually harmful behaviour will therefore be futile if professionals' needs are not explored.

\section{Method}


In contrast to a reductionist approach, the current study did not seek an objective, empirically valid, universal truth; rather, the aim was to explore the multiplicity of interrelated, subjective and often oppositional themes constructed through language (Ussher, 1999). As language is the basis upon which individuals structure and make sense of their experiences, discourses are directed towards the aim of presenting a particular view of social reality. Discourses are therefore made, and exist, in the social world, which each individual actively shapes (Miller \& Hoogstra, 1992).

This study utilised Thematic Analysis (TA) to explore both consistent and variable 'themes', while also drawing upon a discursive perspective to examine the influence of the meaning of wider social, political and linguistic structures and practices that permeate practice surrounding the assessment and management of young people with sexually harmful behaviour. TA combines elements of grounded theory, positivism, interpretivism, and phenomenology, and applies them to the research context. TA is therefore a highly flexible approach to analysing textual data, as there is no one particular way of undertaking analysis (see Boyatzis, 1998; Tuckett, 2005).

A discursive analytic approach (see University of Auckland, n.d.) explores commonalities and differences embedded within text, focusing primarily upon the proxy experience of individuals, including perceptions, feelings, and knowledge as represented within the text (Bernard \& Ryan, 1998). In opposition to searching for explanations, the current study was loyal to the evocation of multiple discourses rather than seeking to discover one historical truth (Spence, 1982); therefore, a pluralistic methodological approach was adopted to both analyse and interpret narrative data provided by participants.

\section{Participants}

Two YOSs were approached in the South of England in order to recruit participants. All suitably qualified staff who could potentially work with sexually harmful young people were contacted (around 20 practitioners in each service). In terms of selection criteria, participants recruited to the study were required to be educated to a minimum of undergraduate degree level, registered as Social Workers and/or Probation Officers within the UK, and to have a minimum of 1 year of experience 
supervising young people with sexually harmful behaviour. As convictions for sexual offending in young people are relatively rare (for example only 12 and 3 respectively were convicted in the year in question in the two regions in question), the latter criterion reduced the sampling frame further to likely around 10 practitioners in total. The achieved sample of 5 practitioners, while acceptable for a qualitative, exploratory enquiry, does support the possibility that there may have been anxiety in divulging experiences and emotions felt in relation to the client group, in line with Baker \& Edwards (2012) notion of 'hidden' or 'hard to access' populations. The researcher had met with participants on a number of occasions previously, due to the being a freelance trainer in the field; this provided a suitable level of professional distance from participants, while having a highly developed understanding of issues that may arise for participants, all of which could be argued to increase the quality of narratives obtained. Practitioners' ages ranged from 30 to 50 years old, with a mean age of 42 years. Of these, two practitioners were female and three were male. Regarding ethnicity, two practitioners defined themselves as White British, one as Sri Lankan, and two as Black Caribbean, with English as the first language of all practitioners.

\section{Procedure}

After ethical approval, two YOSs were approached to participate in the study. The purpose was to access authentic, 'no holds barred' stories, with the researcher positioned as an 'outsider' to each service. Participants in each service volunteered after being contacted via email following initial discussions with each respective Head of Service and were each provided with a 'study briefing' outlining the nature of the study to be conducted and their potential role within the research process. All participants read the information briefing approved by the University of Portsmouth Scientific Ethics Committee prior to commencing each audiotaped interview in private office space within their respective service locations, and were each reminded of the content of the briefing before commencing the interview. 
In addition, each participant read and signed an informed consent form to ensure adherence to ethical guidelines. Five interviews were conducted and audio-recorded, each ranging in length from 42 minutes to 82 minutes. Each interview aimed to be a collaborative venture in understanding a 'conversation with a purpose' (Bingham \& Moore, 1959), using a semi-structured focused interview schedule (Merton, Fiske, \& Kendall, 1990). In an effort to avoid directive or closed questions or interpretations, the interviewer adopted a stance of talking back to the interviewee (Griffin, 1990); in this way, questions were used to promote a reciprocal dialogue with which to explore key themes. Following completion of the interview, participants were thanked and debriefed, with the additional option of an informal conversation regarding the purpose of the study.

The rationale for ceasing data collection after interviews with five participants was underpinned by the notion that a small number of participants within qualitative research is justifiable when attempting to access hidden, or difficult to engage populations. Given the nature of this study (i.e. exploring forensic practice with sexually harmful adolescents), the fact practitioners may have felt to some degree that their experiences were being 'exposed', and the resulting possible anxiety that may have been ignited in some participants surrounding their perception of the researcher's own views regarding practitioner competency/confidence, this small sample is arguably considered 'hidden' or 'hard to access'. Additionally, this study aimed to acknowledge 'multiple truths', rather than a 'universal truth'; therefore, the researcher identified with the notion proposed by Becker (2012) that "one interview is sometimes quite sufficient to establish that something is possible" (Baker \& Edwards, 2012; p. 15). The richness within each narrative and the high level of consistency in issues raised between participants, gave the authors confidence that they had more than enough data with which to develop meaningful themes.

\section{Data analysis}

Thematic Analysis (TA) does not generally involve a microanalysis of language use; rather, this approach identified where consistent or variable themes existed as socially produced. Verbatim transcriptions were produced of the interviews, including pauses and repeated words used by either 
the interviewer or interviewee. Initial codes were identified and cross-referenced for emerging patterns of variability and consistency, and for the functions and effects of specific discourses. Overarching themes noted across the initially coded data were labelled and significant statements extracted and organised into clusters, then checked and re-checked against the taped interviews and examined for differences and commonalities both within and across themes.

The process of identifying and acknowledging the notion of 'themes' identified within the data set under examination is open to potentially multiple interpretations, due to the fact that if they "[...] 'reside' anywhere, they reside in our heads from our thinking about our data and creating links as we understand them" (Ely, Vinz, Downing, \& Anzul, 1997, pp. 205-6). Given TA is considered to be a highly flexible approach, the study adhered to the 15 -point checklist of criteria for good thematic analysis as proposed by Braun and Clarke (p. 96) to act as a framework and instil 'good practice' within the researcher.

\section{Results}

An overarching theme of 'systemic unease' emerged from the experiences of practitioners, which contained two sub-themes surrounding 'unease with the self, and wider YOS personnel' and 'unease working with partner agencies'.

Systemic unease: unease with the self, and wider YOS personnel.

All practitioners openly discussed their initial response when allocated their first sexually harmful young people to supervise. The extract below positions sexual harm as a specialised offence where the lack of knowledge evoked a sense of unease, illustrating this as a need to increase self-efficacy to supervise cases:

"erm, I remember thinking, um, I don't know how to deal with this because I haven't got the, I, I thought it was a specialised area and I didn't have the knowledge base to deal with it [...] you have to know what you're doing or you have to have, um, a certain level of understanding" (participant 1) 
In contrast, comparing sexual offences to 'non-sexual' offences was an alternative approach deployed by some practitioners to attempt to manage any sense of unease:

"[...] I'd be quite happy to, to work with somebody who's committed a violent robbery or a violent burglary, whereas somebody's committed a sexual offence, oooooerr, yeah, l've, l've still got those feelings of, I actually wouldn't know what to do with you" (participant 2)

Practitioners may therefore attempt to make meaning of sexually harmful behaviour by exploring the relevance of their own knowledge base of other types of offending behaviour in an effort to manage any unease experienced, while simultaneously questioning their own competency. While youth justice practice involves acquiring knowledge surrounding those factors that are associated with offending behaviour more generally, and the development of empathic professional relationships with young people, practitioners did not acknowledge the value of their own general skills, experience, or existing knowledge base. Rather, both elements were of questionable relevance when supervising young people with sexually harmful behaviour. This may serve the function of distancing the self from others (i.e. the young person) to regulate the level of unease felt, from "[...] erm, just kind of like, the fear about if something went wrong erm" (participant 1) to being "filled with [..] anxiety about it and feeling a bit out of my depth with that" (participant 2).

One possible method to establish a sense of professional competency was conveyed by one practitioner as follows:

"And I think that there might be some behaviours that, that are abhorrent to me personally, [..] but I have, the role that I have is to look at it based on the values and the underpinning principles that I have within my job" (participant 4)

The sense of 'abhorrence' felt is countered through placing the young person within a wider value base regarding the nature of the role of the practitioner; negotiating professionalism through efforts to remove the 'personal', instead focusing upon their own functional role. The potential impact of this approach, however, may unhelpfully affect an authentic approach to the development and 
maintenance of a therapeutic relationship between the practitioner and the young person. This notion was identified by one practitioner in the following way:

"[...] I mean erm, what's said to reduce offending is, is the relationship they have with their, with, with their erm probation officer or YOT officer and certainly, you know, if [laughs] if erm the off, the young person senses that degree of disgust as it were, or, or abhorrence then, there not gonna, their work isn't going to be as effective as it can be" (participant 1)

The impact of unease felt by two practitioners was also expressed during interview as they reflected on approaches to providing practical support to young people through intervention:

"[..] I might not be aware of it, maybe that's my own naivety but what do we do with young people that sexually harm? What do I do when I'm sat in a room with a young person that's sexually harmful? Do I have to cover certain things? Is there a programme that I should be following?" (participant 4)

"[...] I think because I'm more aware of my deficiencies in my own training needs that I would actually do more harm than good and wouldn't be able to sufficiently manage the risk [...]and actually get somebody to gravitate from what would be perhaps a low level sexualised behaviour to somebody who gravitates to the more serious ones" (participant 2)

These extracts are positioned on a continuum from questioning how to intervene most effectively, to being reluctant to intervene to minimise the risk of doing more harm than good. This presents a dichotomous contrast between practitioners who self-question what may or can be done to provide support to young people, to those who feel a sense of unease regarding the potential to create further harm to possible future victims, beyond that of the victim(s) of the young person's current offence, or the young person themselves.

Both accounts illustrate an implicit, underlying assumption; the young person may become a victim of ineffective or inappropriate supervision by practitioners. The risk of further sexual offending by the young person is internalised by practitioners, who may feel a sense of professional responsibility for any possible further offences in the future, thus ultimately impacting upon the self 
as they develop a therapeutic alliance (i.e. being perceived as a credible human in an 'enabling' profession). As a direct consequence, the positioning of responsibility for future risk of offending rests with the practitioner, rather than being positioned within a framework of psychological 'selfmanagement' by the young person through the development of internal 'constructive' risk management control measures. Effective practice positions resistance, ambivalence, and motivation to adopt pro-social alternatives to offending within the young person (e.g. the internal conflict between where they are now in life and where they may wish to be in the future) facilitated by the practitioner, rather than the resistance or ambivalence to change being positioned between the practitioners' own wishes and desires, and those of the young person (Miller \& Rollnick, 2012). These extracts however, highlight the latter of these two approaches to practice in youth justice may be more common, with the consequence ultimately further perpetuating feelings of unease with the self as an effective and credible practitioner.

A wide range of coping strategies to manage unease with the self were expressed by practitioners:

"I ask a million questions [...] as to right, how do I feel about working with you? Do I still feel upset? Am I angry? Am I, because in order to be able to be supportive to you I've gotta acknowledge that, to be able to move forward in supporting you [...] now I go in where it's much more the level of I need to understand and then I can work my feelings and thoughts from there [..] rather than from disgust" (participant 3)

This narrative illustrates the positive impact of personal reflection, demonstrating a noticeable shift from historically feeling 'disgust' and consciously self-questioning anything practitioners may feel about the young person on first meeting, to developing a more empathic approach in their current practice, by 'needing' to explore the young person's perspective first. This places the young person at the centre of developing an understanding of their life, and from there exploring the repertoire of emotions felt by the practitioner based upon information disclosed by the young person during supervision. The capacity and scope for practitioners to find space to reflect after initial interaction with the client may therefore be key to the management of unease. 
Other strategies to manage unease included emotional side-stepping, instead focusing upon the presenting behaviour of the young person, rather than upon how the practitioner may feel at the time:

"[...] for the people who are on the receiving end of it is that it will be a very distressing traumatic experience quite likely, but actually in terms of adolescent development is to put the horror of being horrified to one side and actually think about it as another adolescent behaviour and think about how we work with that...in a more measured, and less horrified way" (participant 5)

Or consciously normalising the use of moral judgments by ranking sexual offences against each other:

"[...] we do put moral judgements on different types of behaviours that might not necessarily be acceptable in the general scheme of things but you will, in, you will morally rank them kind of like that's worse than kind of like molesting a child is worse than kind of like, you know, potentially indecently assaulting an adult female for example" (participant 2)

These strategies in the long run may ultimately impact unhelpfully upon the ability to develop meaningful interpersonal relationships with the young person.

The need for appropriate supportive environments was expressed by practitioners to cope with feeling unease, which was considered as a collaborative and mutually enriching experience for both themselves and management teams overseeing their practice:

"I sometimes think that managers don't, don't understand their staff, that they can work with them for quite a long time but they don't actually, and we will assume that everyone will have the same response to sexually harmful behaviour and it's just like oh, did you find that really difficult and was it [..] is actually is that understand us as individuals [...] managers seem to think it's only staff who need to talk about stuff reflectively, I don't know, maybe when you get to that level is somehow you don't need that anymore $[. . .]^{\prime \prime}$ (participant 5)

Practitioners identified that both themselves and their managers may also experience unease, and that while supervision may be done to practitioners, realigning to a position of collaborative 
supervision with practitioners may help to nurture practice. Developing a therapeutic alliance between managers and practitioners therefore has the potential to impact across all team members in a mutually beneficial way, although such opportunities need to be both created and utilised by service managers. This is of particular relevance, given a recent UK survey of social workers highlighted the distinct lack of appropriate supervision within their department, with over one third stating they felt supervision was low on their own organisations' priority list (McGregor, 2013). Supervision arrangements, however, may be best provided through mechanisms external to their own service:

"[...] proper clinical supervision with somebody who is completely at ease with, yeah, talking about stuff that, that can feel quite uncomfortable and, and yeah, that we have that completely separate from line management quality assurance performance indicator type supervision, that we have a space where we can really go and sit in that we don't do that for ourselves but that we have somebody who facilitates that for us" (participant 5)

Exposing the core self as vulnerable requires sensitive negotiation during supervision. The separation of emotional responses to practice from line managers through the use of external clinical supervision may therefore be an effective approach to cope with unease. Feeling confident in line with managers' capacity and skills to provide clinical supervision arrangements and questioning whether their skills are aligned to the requirements of practitioners in order to meet their emotional needs is a potentially contentious, yet vitally important debate if the supervision of young people by practitioners is to be meaningfully supported.

\section{Systemic unease: unease with working practices in partner agencies.}

A recurring narrative during interview involved practitioner experiences of other agencies such as educational establishments/providers, housing departments, and the police perceiving young people who sexually harm as 'different' from other young people who commit non-sexual offences: 
"[...] I think that there's a real strong message that if you are sexually harmful, there's something wrong with you [..] there's something wrong with you and you need to be helped, fixed, locked up, in a hospital, whatever it is, there's something wrong with you and there's some inherent [..] fuck up that needs to be [..] dealt with [..] whereas if you've just, if you've gone and beaten someone up or nicked a car or something, yeah you've made a mistake, you shouldn't have done it [...] you can come back from that [...]" (participant 4)

This illustrates how the paucity of knowledge of empirical research across all partner agencies impacts unhelpfully upon perceptions of sexual harm as an inherent feature of the young person, according to practitioners. Partner agencies may attempt to resolve their own sense of unease by pathologising the behaviour of the young person.

Practitioners also conveyed narratives that incorporated feelings of 'shame' and 'embarrassment' amongst both YOS and wider partner agency professionals in the following way:

"It's the, it's the, it's the embarrassment and the shame that's attached to sexually harmful behaviour as opposed to the boy that's gone out and stolen the car or beaten someone up. In some respects, you, there are, there is a thought process of, well, boys will be boys [...] but this young person, they've done something really bad that's not normal and they need to be [...] fixed [..] there's, there's a mental issue there [..] that's the difference actually, that's the difference $[. .$.$] right, we need to send them to CAMHS [\ldots]]^{\prime \prime}$ (participant 4)

There was evidence in interviews that some agencies (particularly legal professionals) approached the appraisal of these young people in an unsystematic and unprofessional way (as opposed to using structured professional judgement that is standard in assessing forensic risk). This may have been due to limited knowledge of the empirical literature:

"[..] you can almost see magistrates turn their noses up, as it's, it's a, it's a nasty smell [...]" (participant 5) 
"[...] you can see in the court they ask far less questions around sexual behaviour than they do around other things [...] it's like a silence in the court, it's like no-one says anything [..] it's something that they don't wanna you know, let's just deal with this and get it over and done with because it's a bit uncomfortable" (participant 4)

Practitioner observations indicate the explicit discomfort felt by Court officials regarding the young person's behaviour, and the resulting impact upon their experience of Court. As highlighted by one participant, the 'very hostile' Court process positions young people as perpetrators, rather than balancing this view with the fact they are also highly vulnerable:

"[...] these are all vulnerable children that we are working with, no matter what they've done, you know and they need to be safeguarded and to, to, the court environment is quite ho, very hostile, erm, [..] and I would urge [..] it to be more sensitive" (participant 4)

This bias seen in sentencers echoes an international perspective proposed by Urban, St. Cyr, \& Decker (2003), in that the Court process seems to give unequal consideration in practice to the fact that many young people are highly vulnerable due to aversive life experiences. It questions to what extent sentencing guidelines for young people charged with sexually harmful offending are fully operationalised i.e. to consider the circumstances of the offence and "the effect on young people of experiences of loss or of abuse" (Sentencing Guidelines Council, 2009, p. 6). Following sentencing, practitioners also identified their experiences of how other partner agencies attempt to jointly manage sexually harmful young people:

"[...] they wanna just cut them off, they're not good, cut them out of school, so then they lose that social 'how to be normal with females or males', you go to a youth club, or, no longer can you be anywhere without an adult or a staff member so again just drumming in all those 'I am deviant', so then what my kids start to do is 'I'll stay home, can't go nowhere, school don't want me, youth clubs don't want me, nobody wants me' [...]" (participant 3) 
"[...] I think there's a panic, there's like a hysteria around sexual harm, sexually harmful behaviour [..] particularly with schools [...]" (participant 4)

The illustration of 'panic' and 'hysteria' by other agencies may serve the function of rationalising decisions to exclude young people as a robust risk management measure to protect other children within educational settings:

"I think that sometimes we can, you can fall, well not you, I, anyone, can fall into the trap of saying, this is what you've done, you mustn't do that and therefore we've told you not to do it, so therefore we've managed the risk, and [..] that doesn't work...it doesn't work for me, it doesn't work for anyone probably to be told not to do something because it's just like putting a fence around someone, you're restricting them, but you're not actually dealing with the issue" (participant 4)

There is considerable scope for greater awareness of the background risks and needs associated with this vulnerable group of young people, starting with better training for the Youth Offending Team itself and clearly with all agencies with which the young person will be engaged, if effective intervention is to be achieved. The need for agency-wide reflective practice supervision as a vehicle to encourage self-challenge regarding decisions made, would avoid falling into the 'trap' of ineffective risk management practice through the use of external restrictive control measures alone. If the experience of practitioners highlights they themselves may lack the knowledge, skills, and experience to actively support internal constructive control measures, risk management practice becomes futile as external restrictive measures alone will be ineffective in supporting behaviour change. This idea is clearly highlighted by one practitioner in the following way:

“Well, look, we're keeping everybody else ever so safe, because he can't go anywhere and he can't do anything, so we are doing that. Of course, the problem is, is, is at the point at which they are released into the wild, is those skills have been so undermined that actually they're kind of going, well I don't know what the fuck I should be doing anyway...um, and does it help? 
Yes, I suppose in some senses it helps, it helps us feel better about what we're doing [...]" (participant 5)

The use of external restrictive control measures to manage the perceived risk of harm to others may serve the function of assisting agencies with meeting their own needs to manage unease, rather than meeting the needs of the young person. A contradiction with the available research base is therefore identified, as disengagement or detachment from education provision is an established protective factor for health (Carlson et al, 2008), mental health (Doll \& Lyon, 1998), and against offending behavior (Yoshikawa, 1994). As a result, practitioners' experiences of encountering unease by other agencies demonstrates variation in understanding of the role each agency should play in achieving the key aim of reducing recidivism. One practitioner further reinforced this point poignantly:

"[...] they get completely ostracised, that frustrates me because, again, you have the criminal justice system where the kids, these kids are already criminalised, where they are already being punished for their behaviour but in all other aspects, especially for kids where school, social, they then become even more punished than the criminal justice system could ever do to them [...]" (participant 3)

While agencies are primarily concerned with holding the child in mind, how this is translated into front-line practice with young people who sexually harm is open to further intense debate. If the narratives above exemplify the experience of youth justice practitioners, there is a strong possibility that these types of perceptions and feelings surrounding unease are likely to affect a much wider range of lesser-trained or less experienced personnel from different agencies.

\section{Discussion}

Analysis of interview transcripts identified an overarching theme of 'systemic unease' among practitioners, consisting of two sub-themes: 'unease with the self, and wider YOS personnel' and 'unease with working practices in partner agencies'. 'Unease with the self, and wider YOS personnel' included: the questioning of competency to supervise young people with sexually harmful behaviour compared to other adolescent offenders; reflections on the effectiveness of current supervision 
approaches to support practitioners' specific psychological and/or emotional needs; and the need for increased support and supervision (ideally from external providers) to support the psychological and emotional impact of their daily role. The emotional blocking that this sense of unease resulted in may have serious consequences for the delivery of interventions.

Narratives aligned with the literature surrounding the development of a therapeutic alliance as fundamental to effective practice (Ackerman \& Hilsenroth, 2003; Ross, Polaschek, \& Ward, 2008). The key issue to consider is whether emotions and associated feelings of 'disgust' or 'abhorrence' unconsciously emerge or become explicit to the young person throughout their period of supervision. Therefore, the capacity to contain emotions experienced through appropriate expressive channels (e.g. clinical supervision) is paramount for a healthy workforce, and to support effective practice by keeping such issues in perspective. The suggestion of emotional detachment may therefore be a key coping strategy used by practitioners that may result in higher levels of resilience when working with young people with sexually harmful behaviour (Clarke, 2004; Fox, 2010).

Additionally, these narrative accounts presented an unhelpful perception in relation to the research literature on recidivism patterns of those young people who sexually harm, which demonstrates a higher likelihood of non-sexual recidivism than sexual recidivism (Caldwell, 2002, 2010; Letourneau \& Miner, 2005; McCann \& Lussier, 2008; Reitzel \& Carbonell, 2006). Practitioners attitudes may, in part, be explained through the permeation of dominant societal discourses presenting "the image of sex offenders in the media as incurable human predators" which "influences public perceptions and legislative decision-making" (Magers, Jennings, Tewksbury \& Miller, 2009, p. 133).

'Unease working with partner agencies' exposed a potential naivety and taboo associated with young people with sexually harmful behaviour amongst other professionals, in particular within the Court system and educational establishments. Pathologising the young person's behaviour was a consistent feature in relation to partner agencies with an emphasis on risk, control, and restriction. It also once more, failed to acknowledge the research literature surrounding sexual offending in 
adolescents, including the impact of childhood trauma and negative life events such as sexual victimisation, caregiver inconsistency, and exposure to physical violence within a family context, all of which are risk factors contained within the risk assessment tools practitioners may be using (Juvenile Sex Offender Assessment Protocol-II; Prentky \& Righthand, 2003; Estimate of Risk of Adolescent Sexual Offence Recidivism; Worling \& Curwen, 2001). Therefore, a medicalised position to understanding the behaviour in question reinforces an unhelpful approach to understanding the heterogeneity of sexually harmful young people, given the multifactorial pathways that may lead to such behaviour including neurobiology (O'Connor \& Rutter, 1996), temperament (Kagan \& Snidman, 2004), family context, and individual variables (Letourneau, Schoenwald, \& Sheidow, 2004).

In contrast to Almond (2013), our participants did not indicate "a sense of purpose and direction" (p. 9), or that line managers were providing high levels of supervision and support to manage cases. Like Masson and Hackett (2004), the study highlights a continuing sense of lack of support and training in relation to managing this vulnerable group of young people and also concurs with findings in relation to working with adult sex offenders (Epps, 1993; Farrenkopf, 1992; Lea, Auburn and Kibblewhite (1999).

\section{Study limitations}

The current study used a sample of five experienced social workers/probation officers practicing within two YOSs in England and Wales, as it did not seek to find a single 'truth' or 'knowledge'. Nevertheless, the study uncovered a number of issues which unfortunately echo rather than revoke recurrent findings over the last two decades in relation to lack of support and training (Griffin \& Beech, 2004; Masson \& Hackett, 2004). These issues should be explored with larger samples of professionals and paraprofessionals (i.e. professionals qualified in allied disciplines such as social work or probation, rather than being qualified in forensic and/or clinical psychology) working with under-18s in diverse forensic contexts (secure and community settings; health and criminal justice settings).

\section{Implications}


Three pertinent issues have been illuminated by this small but telling study, which need further investigation and elaboration. First is the need to explore the specific training, supervision and support needs within the youth justice profession for those working directly with young people. Within the context of the current Youth Justice System in the UK (and potentially elsewhere), an obvious and significant omission in the set-up of most services is that of adopting an evidence-based, psychologically informed perspective, underpinned by research evidence from the discipline of forensic psychology. This may well be a direct consequence of services consisting primarily of both unqualified youth justice practitioners and those holding qualifications within allied disciplines other than forensic psychology. Recent commentators would say that even in the world of correctional psychology itself, evidence-based practice is often neglected due to the pressures of focussing in an imbalanced way on risk management (Gannon \& Ward, 2014). It may not be surprising then that knowledge, training and an emphasis on the therapeutic alliance as the vehicle of change has been sacrificed in the allied field of youth justice. If these findings stand with larger samples of practitioners, the obvious way to remedy it is through greater investment in training, which may be unlikely to happen in the current atmosphere of financial austerity.

Second, there could well be a need to improve communication and training in allied professions such as sentencing and education. An improvement in relationships and a better knowledge and understanding of the client group amongst all involved is likely to yield a more ethical and effective approach to supporting these young people. A solution to this lies in relation to the third issue as follows.

A strong resonance can be seen between the narratives above and Gannon and Ward's (2014) perspective regarding the 'dual relationship'. There is clear evidence above of tensions between the delivery of psychologically informed interventions within services to promote evidence-based practice on the one hand, and that of risk indicators being 'prioritized to the detriment of longer term psychological solutions to that risk' (p. 14). A particular dilemma exists for youth justice practitioners as they seek to: fulfil their statutory responsibilities regarding the management of risk of future 
harmful behaviour through rehabilitation practices; manage the imposition of Court ordered sanctions where necessary; and additionally manage young people's personal vulnerability, safety and wellbeing given the client group are under 18 years of age. This is all attempted within the hitherto described context of a perceived lack of training, supervision and support. Additionally, the 'core normative conflict created by practitioners' varying ethical allegiances' (Ward, 2013, p. 92) is ever more prominent within the Youth Justice System in the UK. A diverse array of professionally qualified (and unqualified) practitioners from education, health, youth work, probation, and social work with differing ethical and moral perspectives and functional roles (as can be clearly seen in the narratives above), further compounds the challenge to finding ethical and moral unity in practice.

Ward (2013) suggests one way forward is to adopt a 'moral acquaintance model' in which the needs/desires of all those involved in the management relationship (including offender, therapist, sentencer, teacher, victim) are given voice, respect and impact on the decisions regarding how to move the (in this case) young person towards a more pro-social life. Drawing from each distinct input, a set of common norms, aims and principles is derived which all agencies and the young person themselves has bought in to. In addition to a more robust set of principles with which to work, this approach should have an enabling role in facilitating greater knowledge and understanding of the client group and a more coherent, effective multi-agency approach to managing the young person.

Another useful approach for bolstering resilience in practitioners dealing with challenging clients is the Model of Dynamic Adaptation (Clarke, 2004, 2008, 2011). It incorporates a range of individual static (e.g. age, gender), stable (e.g. coping style) and dynamic factors (e.g. changes to organisational structures), and critical occupation factors (e.g. colleague relationships, policies and procedures) all of which are important when also considering the current economic climate, with many services integrating resources to reduce expenditure. Those relevant factors for each practitioner are assessed and supportive interventions put in place to maximise practitioner well being, which has been considered to be an effective approach for those professionals working specifically with adult sex offenders (see Clarke \& Roger, 2002), and within other professional 
occupations. Its features complement and support a holistic, responsive and strengths-based approach now prioritised in working with clients in correctional services.

\section{Diversity considerations}

Regarding participants, this research study engaged professionals who represented a diverse range of ages, length of experience, qualifications/backgrounds, gender, race, and ethnicity. This demonstrates the authors' clear commitment to an inclusive approach when exploring practitioners' experiences in forensic practice with young people displaying sexually harmful behaviour, and to minimise any potential negative impact by presenting findings from a homogenous sample.

The use of a qualitative methodological approach also facilitated participants to openly express their experiences, with no barriers in place to hinder communication. This was enhanced by the use of a clear pre-interview briefing being sent to all interested participants in English (as this was the first/preferred language of all participants, as self-reported to the researcher prior to interviews commencing), using language which was SMOG tested to ensure the text could be understood by an individual which reflected the UK national average reading age of 11 years old.

Given the nature of this study, questions surrounding the influence and/or impact of culture upon practitioner experiences in forensic practice were not fully explored. As a future study, this may be a helpful area to focus upon, when considering whether culture may impact (positively or negatively) upon forensic practice with young people who display sexually harmful behaviour. As with all qualitative studies, the researcher offers their interpretation of narratives exposed during interview sessions, hence being subjective in nature. Therefore, future studies may benefit from reflecting more explicitly upon the potential impact of the researchers own experience, age, gender, sexual orientation, and ethnicity when interpreting textual data. The advantage of adopting a qualitative approach to this research study is that a single truth was not sought. Therefore, it is proposed that the use of qualitative studies exploring sensitive, 'hidden' or 'hard to reach' narratives, such as those highlighted within this research study have the potential to provide a greater degree of consideration of the impact of diversity upon research findings, when compared to laboratory based/simulated 
experiments which may not focus upon interpreting results with diversity issues in mind, such as sexual orientation, socioeconomic status, race, gender or ethnicity, unless these were an integral feature of the original research question posed.

\section{Conclusion}

This study uncovered a considerable lack of ease in five youth justice practitioners working with sexually harmful young people. In doing so it laid out some pertinent issues and questions that certainly merit further exploration in order to more precisely determine the types of training and support that would be most meaningful and effective for promoting best practice for such young people.

Unease was characterised by a lack of self-efficacy in supervising this population that in turn was underpinned by a perceived lack of training and support. It was also strongly reflected in concerns about the naivety towards and pathologising of young people by partner agencies. Despite the significant efforts made by practitioners to support interventions with young people within the youth justice system, the scarcity of evidence-based input from forensic psychologists within YOSs regarding initial training and on-going support needs to be addressed. This presents a challenge to both Central and Local Government Departments responsible for the performance of youth justice services in the UK, as these have over-relied upon paraprofessionals to deliver psychological practice, despite lacking any formal qualifications or training in forensic psychology. Adopting a revised approach to training and supervision may also facilitate greater awareness and understanding in partner agencies through better multi-agency working in which the ethical stances of all factions are given voice.

Methods to identify practitioner/manager needs and to build resilience using an evidencebased framework such as the Model of Dynamic Adaptation are proposed. This may facilitate the identification of the needs of professionals working in such emotionally demanding occupations, while also going some way to addressing conclusions within the Munro review of child protection systems in England (Munro, 2011). Our future endeavours, both research and practice must ensure that the 
needs of both the child and the practitioner are placed at the centre of service provision if we are not to enter a third decade in which neither are supported consistently or effectively.

\section{References}

Ackerman, S. J., \& Hilsenroth, M. J. (2003). A review of therapist characteristics and techniques positively impacting the therapeutic alliance. Clinical Psychology Review, 23(1), 1-33.

Allardyce, S. (2016, April 12). A global concern: why sharing youth justice practice is a smart move. [web log message]. Retrieved from http://www.cycj.org.uk/a-global-concern-why-sharing-youthjustice-practice-is-a-smart-move-2/

Almond, T. (2013). Working with children and young people with harmful sexual behaviours: Exploring impact on practitioners and sources of support. Journal of Sexual Aggression, 1-21.

Baker, S. E., \& Edwards, R. (2012). How many qualitative interviews is enough? Expert voices and early career reflections on sampling and cases in qualitative research. National Centre for Research Methods. Retrieved from http://eprints.ncrm.ac.uk/2273/4/how many interviews.pdf

Becker, J. V. (1998). The assessment of adolescent perpetrators of childhood sexual abuse. The Irish Journal of Psychology, 19(1), 68-81.

Bernard, H. R., \& Ryan, G. (1998). Text analysis: Qualitative and quantitative methods. In H. R. Bernard (Ed). Handbook of Methods in Cultural Anthropology. Walnut Creek, CA: Alta Mira Press.

Bingham, W., \& Moore, B. (1959). How to Interview. New York: Harper International. 
Boyatzis, R. E. (1998). Transforming Qualitative Information: Thematic Analysis and Code Development. London: Sage.

Braun, V., \& Clarke, V. (2006). Using thematic analysis in psychology. Qualitative Research in Psychology, 3(2), 77-101.

Bremer, J. F. (1998). Challenges in the assessment and treatment of sexually abusive adolescents. The Irish Journal of Psychology, 19, 82-92.

Caldwell, M. F. (2002). What do we not know about juvenile sexual reoffense risk? Child Maltreatment, 7, 291-302.

Caldwell, M. F. (2010). Study characteristics and recidivism base rates in juvenile sex offender recidivism. International Journey of Offender Therapy and Comparative Criminology, 54, 197-212.

Carlson, S. A., Fulton, J. E., Lee, S. M., Maynard, L. M., Brown, D. R., Kohl III, H. W., \& Dietz, W. H. (2008). Physical education and academic achievement in elementary school: data from the early childhood longitudinal study. American Journal of Public Health, 98(4), 721-727.

Clarke, J., \& Roger, D. (2002). Working Therapeutically with Sex Offenders: The Potential Impact on the Psychological Well-Being of Treatment Providers. In Falshaw, L. (Ed.) Issues in Forensic Psychology No. 3: The Impact of Offending. Leicester: British Psychological Society.

Clarke, J. (2004). The Psychosocial Impact on Facilitators of Working Therapeutically with Sex Offenders: An Experimental Study. Unpublished PhD thesis, University of York, UK. 
Clarke, J. (2008). Promoting professional resilience. In Calder, M. (Ed.), Contemporary Risk Assessment in Safeguarding Children. (pp. 166-182). Dorset: Russell House.

Clarke, J. (2011). Working with sex offenders: Best practice in enhancing practitioner resilience. Journal of Sexual Aggression, 17(3), 335-355. DOI: 10.1080/13552600.2011.583781

Collins, S., \& Nee, C. (2010). Factors influencing the process of change in sex offender interventions: Therapists' experiences and perceptions. Journal of Sexual Aggression, 16(3), 311-331.

Cunningham, M. (2003). Impact of trauma work on social work clinicians: Empirical findings. Social Work, 48(4), 451-459. DOI: 10.1093/sw/48.4.451

Centre for Youth and Criminal Justice (CYCJ) (n.d.). A Guide to Youth Justice in Scotland: Policy, Practice and Legislation (Managing Risk of Serious Harm). Retrieved from CYCJ Website: http://www.cycj.org.uk/wp-content/uploads/2015/06/Section-5-Managing-Risk-of-Serious$\underline{\text { Harm.pdf }}$

Doll, B., \& Lyon, M. A. (1998). Risk and resilience: Implications for the delivery of educational and mental health services in schools. School Psychology Review, 27(3), 348.

Ely, M., Vinz, R., Downing, M., \& Anzul, M. (1997). On Writing Qualitative Research: Living by Words. London: Routledge.

Ennis, L., \& Horne, S. (2003). Predicting psychological distress in sex offender therapists. Sexual Abuse: A Journal of Research and Treatment, 15(2), 149-157. 
Epps, K. (1993). A survey of experience, training and working practices among staff working with adolescent sex offenders in secure units. In N. K. Clark, \& G. M. Stephenson (Eds.), Sexual Offenders: Context, Assessment and Treatment. (pp. 19-26). Leicester: BPS.

Farrenkopf, T. (1992). What happens to therapists who work with sex offenders? Journal of Offender Rehabilitation, 18(3-4), 217-224. DOI: 10.1300/J076v18n03_16

Figley, C. R. (1993). Coping with stressors on the home front. Journal of Social Issues, 49(4), 51-71.

Fox, A. (2010). Investigating the Factors that Contribute to Staff Well-Being and Professional Resilience at a Dangerous and Severe Personality Disorder Unit. (unpublished MSc thesis). University of York, York.

Franey, K. C., Viglione, D. J., Wayson, P., Clipson, C., \& Brager, R. (2005). An investigation of successfully treated adolescent sex offenders. Journal of Child Sexual Abuse, 13(3-4), 295-317. DOI: 10.1300/J070v13n03_15

Gannon, T. A., \& Ward, T. (2014). Where has all the psychology gone? A critical review of evidencebased psychological practice in correctional settings. Aggression and Violent Behavior, 19, 435-446.

Great Britain. Criminal Justice Joint Inspection (2013). Examining Multi-Agency Responses to Children and Young People Who Sexually Offend: A joint inspection of the effectiveness of multi-agency work with children and young people in England and Wales who have committed sexual offences and were supervised in the community. London: Criminal Justice Joint Inspectorate.

Great Britain. Sentencing Guidelines Council. (2009). Overarching Principles: Sentencing Youths. London: Sentencing Guidelines Council. 
Griffin, C. (1990). The researcher talks back. In W. Shaffir, \& R. Stebbins (Eds). Experiencing Fieldwork. Newbury Park, CA: Sage.

Griffin, H., \& Beech, A. (2004). Evaluation of the AIM Framework for the Assessment of Adolescents Who Display Sexually Harmful Behaviour: A report for the Youth Justice Board. London: Youth Justice Board.

Grimshaw, R. (2008). Young People Who Sexually Abuse: Source Document. London: Youth Justice Board.

Hackett, S., \& Masson, H. (2006). Young people who have sexually abused: What do they (and their parents) want from professionals? Children \& Society, 20(3), 183-195. DOI: 10.1002/CHI.873

Hackett, S., Phillips, J., Balfe, M., \& Masson, H. (2012). Family responses to young people who have sexually abused: Anger, ambivalence and acceptance. Children \& Society, 1-12. DOI: 10.1111/j.10990860.2012.00471.x

Henniker, J., Foster, J. M., \& Griffin, H. L. (2000). A Study Within Greater Manchester of the Professional Response to Young People Who Sexually Abuse Others. The Youth Justice Trust, Unpublished.

Home Office (1999). Home Office Guidance to the Probation Service. London: Home Office.

Kagan, J., \& Snidman, N. (2004). The Long Shadow of Temperament. Cambridge, MA: Harvard 
University Press.

Ladwa-Thomas, U., \& Sanders, R. (1999). Juvenile sex abusers: Perceptions of social work practitioners. Child Abuse Review, 8(1), 55-62. DOI: 10.1002/(SICI)1099-0852(199901/02)8:1<55::AIDCAR485>3.0.CO;2-P

Lea, S., Auburn, T., and Kibblewhite, K. (1999). Working with sex offenders: The perceptions and experiences of professionals and paraprofessionals. International Journal of Offender Therapy and Comparative Criminology, 43(1), 103-119. DOI: 10.1177/0306624X99431010

Letourneau, E. J., \& Miner, M. H. (2005). Juvenile sex offenders: A case against the legal clinical status quo. Sexual Abuse: A Journal of Research and Treatment, 17, 293-312.

Letourneau, E. J., Schoenwald, S. K., \& Sheidow, A. J. (2004). Children and adolescents with sexual behaviour problems. Child Maltreatment, 9, 49-61.

Magers, M., Jennings, W. G., Tewksbury, R., \& Miller, J. M. (2009). An exploration of the sex offender specialization and violence nexus. The Southwest Journal of Criminal Justice, 6(2), 133-144.

Masson, H., \& Hackett, S. (2004). The extent and nature of work with adolescents who have sexual behaviour problems: Findings from a survey of youth offending teams in England and Wales. Youth Justice, 4(3), 160-177. DOI: 10.1177/147322540400400302

McCann, K., \& Lussier, P. (2008). Antisociality, sexual deviance, and sexual reoffending in juvenile sex offenders: A meta-analytic investigation. Youth Violence and Juvenile Justice, 6, 363-385.

McGregor, K. (2013). Third of UK's social workers not currently receiving supervision. Retrieved from 
Community Care Website: http://www.communitycare.co.uk/2013/06/18/third-of-uks-socialworkers-not-currently-receiving-supervision/

Merton, R. K., Fiske, M., \& Kendall, P. L. (1990). The Focused Interview: A Manual of Problems and Procedures. London: McMillan.

Miller, P. J., \& Hoogstra, L. (1992). Language as tool in the socialisation and apprehension of cultural meanings. In: T. Schwartz, G. White, \& C. Lutz (Eds). New Directions in Psychological Anthropology. Cambridge: Cambridge University Press.

Miller, W. R., \& Rollnick, S. (2012). Motivational Interviewing: Helping People Change (Applications of Motivational Interviewing) ( $3^{\text {rd }}$ Ed). New York: Guilford Press.

Munro, E. (2011). The Munro Review of Child Protection: Final Report - A Child Centered System. London: Department of Education.

National Children's Home. (1992). The Report of the Committee of Enquiry into Children and Young People Who Sexually Abuse Other Children. London: $\mathrm{NCH}$.

O'Connor, T. G., \& Rutter, M. (1996). Risk mechanisms in development: Some conceptual and methodological considerations. Developmental Psychology, 32, 787-795.

Prentky, R., \& Righthand, S. (2003) Juvenile Sex Offender Protocol-II (J-SOAP-II). Office of Juvenile Justice and Delinquency Preventions' Juvenile Justice Clearinghouse.

Print, B., Morrison, T., \& Henniker, J. (2000). Working with children and young people who sexually abuse: Procedures and Assessment. AIM Project, Manchester. 
Reitzel, L. R., \& Carbonell, J. L. (2006). The effectiveness of sex offender treatment for juveniles as measured by recidivism: A meta-analysis. Sexual Abuse: A Journal of Research and Treatment, 18, 401421.

Ross, E. C., Polaschek, D. L., \& Ward, T. (2008). The therapeutic alliance: A theoretical revision for offender rehabilitation. Aggression and Violent Behavior, 13(6), 462-480.

Severson, M., \& Pettus-Davis, C. (2013). Parole officers' experiences of the symptoms of secondary trauma in the supervision of sex offenders. International Journal of Offender Therapy and Comparative Criminology, 57(1), 5-24. DOI: 10.1177/0306624X11422696

Spence, D. (1982). Narrative Truth and Historical Truth. London: Norton.

Tuckett, A. G. (2005). Applying thematic analysis theory to practice: A researcher's experience. Contemporary Nurse, 19(1-2), 75-87.

University of Auckland. (n.d.). Frequently Asked Questions. Retrieved from University of Auckland, School of Psychology Website: http://www.psych.auckland.ac.nz/en/about/our-research/researchgroups/thematic-analysis/frequently-asked-questions-8.html

Urban, L. S., St. Cyr, J. L., \& Decker, S. H. (2003). Goal conflict in the juvenile court. Journal of Contemporary Criminal Justice, 19(4), 454-479. DOI: 10.1177/1043986203259484 
U.S. Department of Justice National Sex Offender Public Website: Retrieved from NSOPW Website: https://www.nsopw.gov/en/Education/FactsStatistics?AspxAutoDetectCookieSupport=1\#pre petrators

Ussher, J. M. (1999). Women's madness: A material-discursive-intra-psychic approach. In D. Fee (Ed). Psychology and the Postmodern: Mental Illness as Discourse and Experience. London: Sage.

Ward, T. (2013). Addressing the dual relationship problem in forensic and correctional practice. Aggression and Violent Behavior, 18, 92-100. DOI: 10.1016/j.avb.2012.10.006

Weekes, J. R., Pelletier, G., \& Beaudette, D. (1995). Correctional officers: How do they perceive sex offenders? International Journal of Offender Therapy and Comparative Criminology, 39(1), 55-61.

Worling, J., \& Curwen, M. (2001). Estimate of risk of adolescent sexual offence recidivism: The ERASOR (Version 2). In M. Calder (Ed.) Juveniles who Sexually Abuse: Frameworks for Assessment (2nd edition). London: Russell House Publishing.

Yoshikawa, H. (1994). Prevention as cumulative protection: effects of early family support and education on chronic delinquency and its risks. Psychological Bulletin, 115(1), 28.

Youth Justice Board/Ministry of Justice (2015). Youth Justice Statistics 2013/14 - England and Wales. Retrieved from Youth Justice Board Website:

https://www.gov.uk/government/uploads/system/uploads/attachment data/file/399379/you th-justice-annual-stats-13-14.pdf 
Footnotes

i Child and Adolescent Mental Health Services 